\title{
An evaluation of the GSA Nonlinear Static Progressive Collapse Methodology applied to EC 8 Seismically Designed RC Moment Frames
}

\author{
Noble Obeng-Ankamah ${ }^{1}$, Mark Adom-Asamoah ${ }^{2}$ \\ ${ }^{1}$ Sunyani Technical University, Department of Civil Engineering, Sunyani, Ghana \\ ${ }^{2}$ Kwame Nkrumah University of Science and Technology, Department of Civil Engineering, Kumasi, Ghana
}

\begin{abstract}
This study aims at evaluating the progressive collapse potential of $R C$ framed structures designed to Eurocode 8 with varying design ground accelerations and ductility classes. Four typical 11-storey RC framed structures were designed with ground accelerations of $0.10 \mathrm{~g}$ and $0.25 \mathrm{~g}$ at low, moderate and high ductility classes. Analysis of the performance levels and progressive collapse vulnerability of these structures was carried out considering the four column loss scenarios and acceptance criteria specified by the General Service Administration (GSA) document. It was observed that high design ground acceleration and low design ductility classes increase the progressive collapse resistance of $\mathrm{EC} 8$ designed $\mathrm{RC}$ framed structures. This observation is counter-intuitive to the principles underpinning the EC 8 design code as higher design ductility class is expected to enhance the energy absorption capacity or ductility of buildings with same design seismic action but varying ductility classes. It is concluded that the use of GSA to assess buildings designed to EC 8 must be modified to include the effects of both design action and design ductility class of a structure. The location of the lost column was also found to be very influential on the progressive collapse resistance of the structure.
\end{abstract}

Keywords: progressive collapse, nonlinear static, seismic design, reinforced concrete frame

\section{Introduction}

Progressive collapse is a phenomenon that involves the damage of a structural element resulting in the collapse of a disproportionately large part of the structure or the entire structure. Based on this definition, most catastrophic structural failures may be classified under progressive collapse. [1] estimated that 110 cases of collapse were recorded between 1968 and 1971 in United States. Out of this, 22 were categorized as progressive collapse, representing 20\%. Between 1962 and 1971, 495 collapse cases were recorded in Canada with $72(15 \%)$ characterized as progressive collapse (Taylor, 1975). [2]also reported that 225 cases of collapse were recorded in the United States between 1989 and 2000. Significantly, 54\% of these collapse cases were progressive in nature.

Progressive collapse is primarily an issue of vertical loadcarrying capacity of a structure. However, the design of elements of a building may not depend only on vertical loads, but also on lateral loads from actions such as wind or earthquake. Beams, columns or joints of a framed structure may have a larger load-bearing capacity due to the design to wind or seismic actions. These elements would have higher capacities to confine damage to the initially affected area, and consequently prevent progressive collapse [3]. It has been observed from a series of research that, continuity for offering alternate path and stability when a load-bearing element is lost is the best way to prevent progressive collapse of a structure.

Seismic design and detailing of a structure gives it a certain level of continuity, ductility and redundancy, depending on the provisions for the seismic zone and for the ductility class. The mentioned characteristics are extremely important and have a significant influence on the progressive collapse behaviour. A higher ductility improves the capacity of a structure to respond to a sudden removal of a vertical element with an inelastic behaviour and without the failure of other structural elements [4].[5]-[7] found that seismically designed of RC moment frames have inherent ability to resist progressive collapse due to the increase in reinforcement.

The General Service Administration (GSA) has presented practical guidelines for the design to reduce the progressive collapse potential of federal buildings [8]. The Department of Defence (DoD) has also presented a guideline for the new and existing DoD buildings i.e. Unified Facilities CriteriaDepartment of Defence [9]. These guidelines recommend the alternate path method for analysing a structure for its progressive collapse vulnerability. The alternate path analysis method involves removal of a column from four specified locations, which are then analysed. The limits states of the elements are then checked and failed elements are removed. Subsequent analysis results in the redistribution of loading to the adjacent elements. The analysis is repeated until stability is achieved or the whole building fails. Currently, the four methods of analysis namely linear static, linear dynamic, nonlinear static, and nonlinear dynamic are recommended for the alternate path method. This categorization follows the Federal Emergency Management Agency [10] procedures for seismic analysis.

The four methods of alternative path analysis have been investigated in research efforts involving the progressive collapse of buildings in a bid to recommend the most simple and efficient method. By analysing a 2-dimensional reinforced concrete frame, [11] showed that the linear static analysis produces non-conservative results as it does not reflect the dynamic effect caused by the sudden loss of columns. [12] compared the linear static, nonlinear static, and nonlinear dynamic analyses and concluded that a factor of 2.0 


\section{International Journal of Science and Research (IJSR) \\ ISSN (Online): 2319-7064}

Index Copernicus Value (2015): 78.96 | Impact Factor (2015): 6.391

specified in the guidelines for static analyses can produce very conservative result, and also concluded that basically the nonlinear procedure should be used. The phenomenon of progressive collapse is nonlinear in nature, it is, therefore, more reasonable to carry out nonlinear analyses with nonlinear modelling of each element. Among the nonlinear analysis procedures, the nonlinear static analysis has some disadvantages compared to the nonlinear dynamic analysis. [13] indicated that the nonlinear static analysis might result in prediction of larger ductility demand, which means that it would produce conservative results because the load path does not move laterally but vertically.

Even though the nonlinear dynamic analysis procedure is believed to be the most accurate, the complexity of analysis and the extensive computing time involved do not lend itself suitable for design office use. Therefore, the nonlinear static (pushdown) analysis is still very relevant in investigating the collapse behaviour of a structure. As the lateral pushover analysis is widely used to evaluate structural properties such as yield stress, lateral stiffness, maximum lateral load resistance, and ultimate lateral displacement, it is expected that similar useful information may be obtained by the pushdown analysis for progressive collapse.

The nonlinear static analysis procedure, which has been widely used in earthquake engineering field, was adopted in this paper to investigate the structural performance of buildings against progressive collapse. The advantage of this procedure is its ability to account for nonlinear effects without sophisticated hysteretic material modelling and timeconsuming time-history analysis. It also has the ability to determine elastic and failure limits of the structure.

This study seeks to investigate the performance levels of varying design peak accelerations and ductility classes of EC 8 [14] designed RC frame buildings subjected to progressive collapse when assessed using different column removal positions of the GSA nonlinear static methodology. In this study, the vertical pushover analysis or pushdown analysis was applied by increasing the vertical displacement at the location of the removed column to investigate the resistance of the structure against such deformation. Since this nonlinear pushdown method is displacement controlled, the analysis was carried out by increasing displacements to an arbitrary level. The load-displacement curves are plotted, from which yield displacements, ultimate displacements, vertical ductility and the maximum load factors are obtained.

\section{Description of Structural System}

\subsection{Description of Structural Systems}

Four 11-storey moment resistant reinforced concrete models were designed with varying behaviour factors and ductility classes according to Eurocode 8 [14]. Details of the seismic parameters are shown in Table 1.
Table 1: Details of structural configurations

\begin{tabular}{|c|c|c|c|}
\hline $\begin{array}{c}\text { Structural } \\
\text { Reference }\end{array}$ & $\begin{array}{c}\text { Design PGA } \\
(\mathrm{g})\end{array}$ & $\begin{array}{c}\text { Ductility } \\
\text { Class }\end{array}$ & $\begin{array}{c}\text { Behaviour } \\
\text { (q) Factor }\end{array}$ \\
\hline L0.10 & 0.10 & Low & 1.5 \\
\hline H0.25 & 0.25 & High & 5.85 \\
\hline M0.25 & 0.25 & Medium & 3.90 \\
\hline L0.25 & 0.25 & Low & 1.50 \\
\hline
\end{tabular}

A typical plan of the floors is presented in Figure 1. All floors are $3.0 \mathrm{~m}$ high giving a total height of $33.0 \mathrm{~m}$.

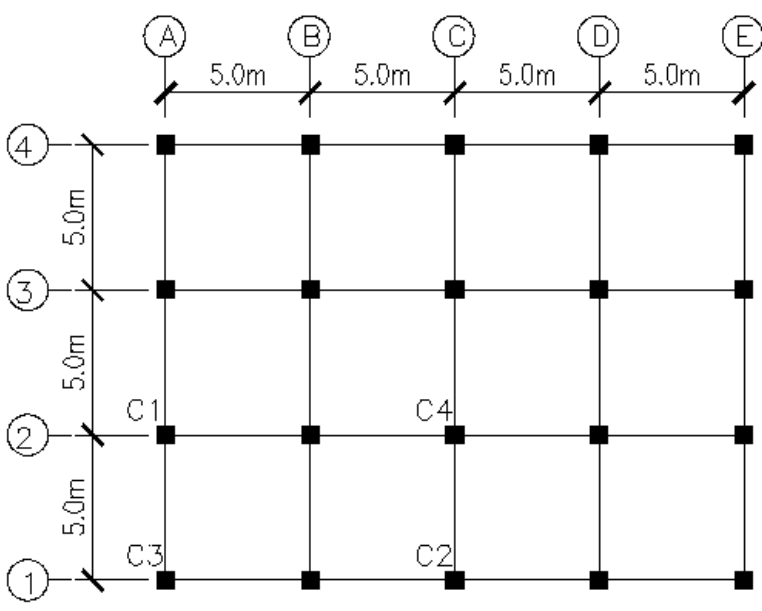

Figure 1: Typical plan of reinforced concrete structure

The structural supports were assumed to be restrained. The compressive strength of concrete used was $30 \mathrm{MPa}$ and the yield strength of the reinforcement was $575 \mathrm{MPa}$. Modulus of elasticity for concrete and steel was $27.0 \mathrm{kN} / \mathrm{mm}^{2}$ and $200.0 \mathrm{kN} / \mathrm{mm}^{2}$ respectively. The dimensions of beams used were $600 \mathrm{~mm}$ high and $300 \mathrm{~mm}$ wide for all floors. Column dimensions were $800 \times 800 \mathrm{~mm}$ for internal columns, $600 \times 600 \mathrm{~mm}$ for side columns and $500 \times 500 \mathrm{~mm}$ for corner columns.

\section{Progressive Collapse Analysis}

The nonlinear static analysis known as the pushdown analysis was employed in this study. This involves a stepwise increase of vertical loads, until a maximum amplified load of $2(\mathrm{G}+.25 \mathrm{Q})$ is reached or the structure collapses. This method has the advantage of accounting for nonlinear effect without sophisticated hysterical materials modelling and time consuming time history analysis. Though it is unable to consider the dynamic effect caused by the sudden removal of columns, it is useful in determining the elastic and failure limits of the structure.

\subsection{Column Loss Scenarios}

Progressive collapse of the models were assessed by considering column loss from the following locations on the ground floor as specified by the [8].

1) Case 1: An exterior column near the middle of the short side of the building

2) Case 2: An exterior column near the middle of the long side of the building

3) Case 3: A column located at the corner of the building

4) Case 4: A column interior to the perimeter 


\section{International Journal of Science and Research (IJSR) \\ ISSN (Online): 2319-7064}

Index Copernicus Value (2015): 78.96 | Impact Factor (2015): 6.391

\subsection{Analysis Procedure}

The U.S. General Services Administration [8] proposes the amplification factor of 2.0 for the static analyses procedures to account for dynamic redistribution of forces. The load combination of the [8] for the analysis is2(Dead Load + $0.25 \times$ Live Load). This load combination is applied only to the span in which a column is removed while unamplified load of (Dead Load $+0.25 \times$ Live Load)is applied in the other spans [15].

\subsection{Acceptance Criteria}

The criteria for the determination of failure due to progressive collapse analysis is in two fold; a local criteria and a global criterion. The local criterion is based on the susceptibility of an individual member to failure in a localised ultimate state such as bending failure, shear failure or axial failure. However, several studies on seismically designed RC frames have shown bending failure is the most common cause of progressive collapse as compared to shear and axial failures. Therefore, plastic hinges were assigned to the structural members. M3 and P-M2-M3 plastic hinges were assigned to the ends of beams and columns respectively. For member rotational limits, limit-state criteria from the GSA guidelines were used [8]. Detailed hinge properties for the members at different performance levels as specified by [16] are given in Figure 2.

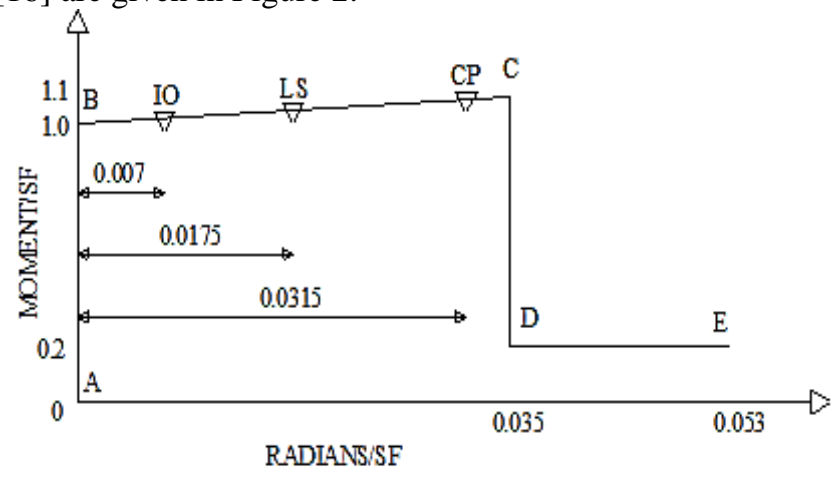

Figure 2: User-Defined moment-rotation hinge properties

The performance levels are Immediate Occupancy (IO), Life Safety (LS), and Collapse Prevention (CP). These levels are based on the condition of the building under gradually increased gravity loads. In this study, three performance levels define these as $0.2 \Delta, 0.5 \Delta$ and $0.9 \Delta$ respectively. Where, $\Delta$ is the length of plastic hinge plateau. A member is considered failed if its plastic hinge rotation at both ends exceeds 0.035rad. A structure is considered vulnerable to progressive collapse globally if it collapses before loading on the collapsing bay reaches $2(\mathrm{G}+0.25 \mathrm{~L})$.

\section{Results and Discussion}

\subsection{Risk of Progressive Collapse using local failure criterion}

In the pushdown analysis, vertical loading was applied to the structure until collapse. As the displacement increase, plastic hinges developed and rotated until collapse according to the user-defined moment hinge rotations properties shown in Figure 2. [8]guidelines recommend a pushdown up to a target load 2(G+0.25Q) for assessing progressive collapse resistance. The state of plastic hinges at this load level is presented in presented in Figures 3 to 6.

It is observed in Figure 3 and Figure 4 that when a column was lost from near the middle of the long side (Case 1) and short side (Case 2) of the buildings, no plastic hinge developed in model L0.25 indicating that they remained in the range of elastic deformation at the target loading. There were only a few plastic hinges formed in the models L0.10 and $\mathrm{H} 0.25$; however, the buildings remained in the immediate occupancy structural performance level. This means that, only limited structural damage occurred. The basic vertical load resisting systems retained almost all their strength and stiffness. Although some minor structural repairs may be appropriate, these would generally not be required prior to reoccupation [16].

Plastic Hinges formed at both joints of all beams connected above the removed column in models H0.25. All the hinges at one end of the beams reached the collapse stage where the vertical load resisting systems had lost all strength and stiffness and so the frame collapses.

Similar observations made for models H0.25 in Cases 1 and 2 were also made for models L0.10 and H0.25 in Case 3, as seen in Figure 5. In Case 3, most hinges in the beams of Model M0.25 reached the life safety performance level. This indicates that significant damage to the structure has occurred but some margin of against either partial or total collapse remains. Although there is no imminent risk of collapse, it would be prudent to implement structural rehabilitation prior to reoccupation [16]. However, in model L0.25, only a few plastic hinges were formed and they all remained in the immediate occupancy level.

Figure 6 shows the states of plastic hinge at the target loading when a column was removed from a location interior to the perimeter (Case 4). It is observed that no plastic hinges were formed in models M0.25 and L0.25. Deformation in these models remained in the elastic stage and hence no damage is expected in them. Model L0.10 developed hinges in beams connected above the removed column. Most of these hinges reached the life safety performance level while the others remained at the immediate occupancy state. Significant structural damage is therefore expected with some margin against collapse remaining. In model $\mathrm{H} 0.25$, hinges reached the collapse state at one end of the beams connected directly above the removed column. Collapse is therefore expected here.

Volume 6 Issue 1, January 2017

www.ijsr.net 
International Journal of Science and Research (IJSR)

ISSN (Online): 2319-7064

Index Copernicus Value (2015): 78.96 | Impact Factor (2015): 6.391

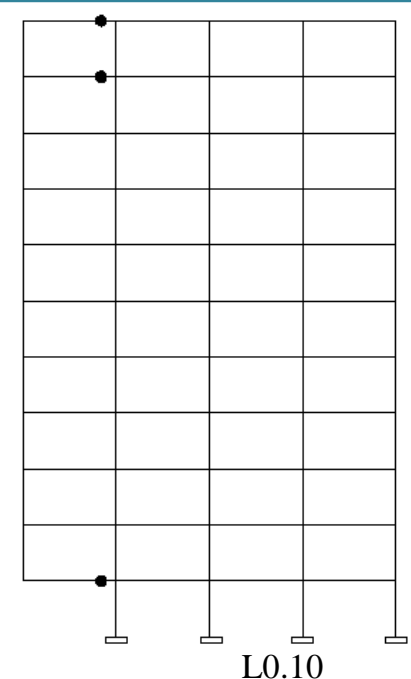

Immediate occupancy

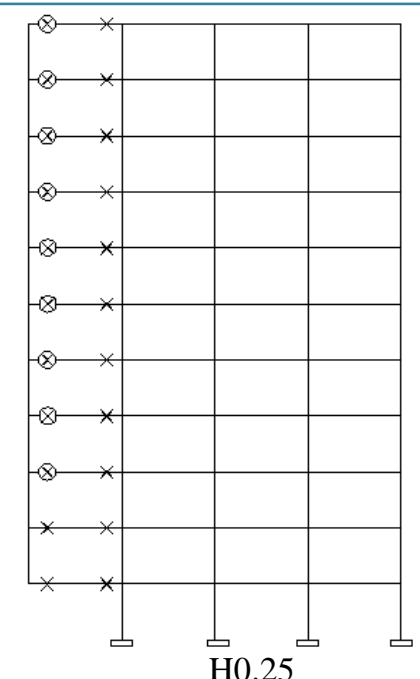

$\bigcirc$ Life safety

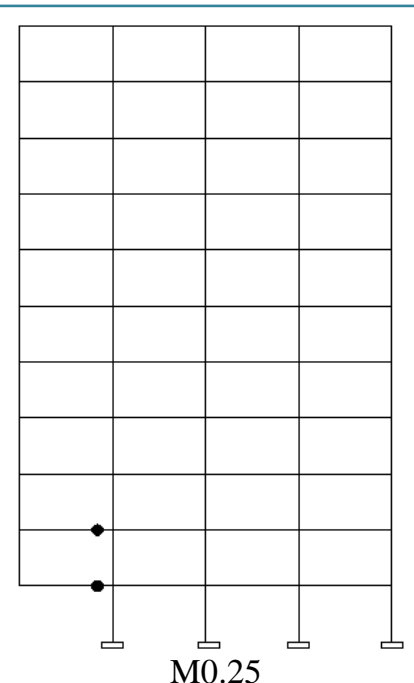

$\otimes$ Collapse Prevention

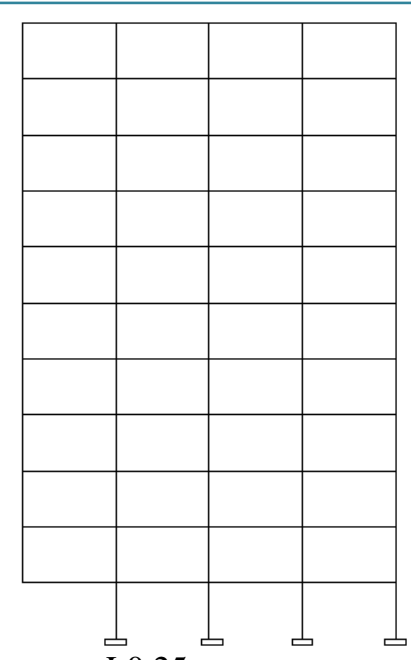

L0.25

$\times$ Collapse

Figure 3: Plastic Hinge Rotations at 2(G+0.25Q) for Case 1

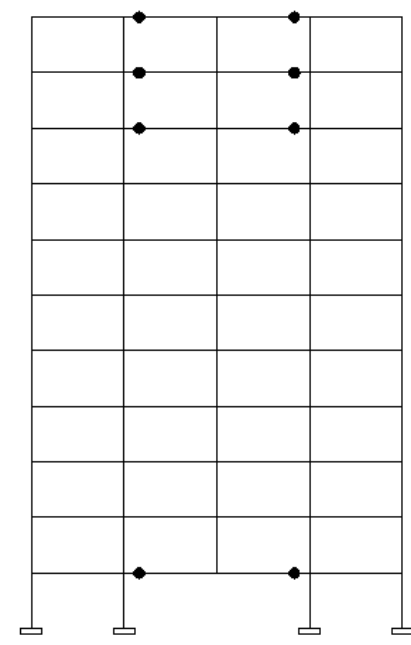

L0.10

Immediate occupancy

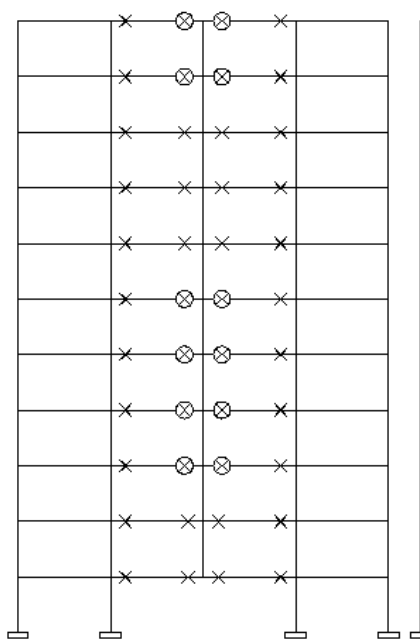

H0.25

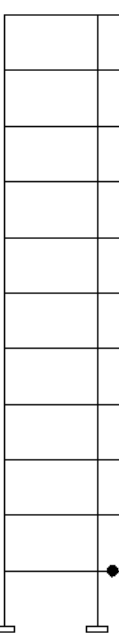

M0.25

$\otimes$ Collapse Prevention

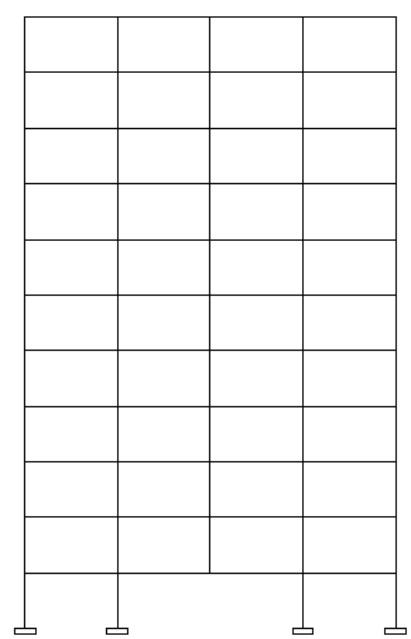

L0.25

$\times$ Collapse

Figure 4: Plastic Hinge Rotations at 2(G+0.25Q) for Case 2

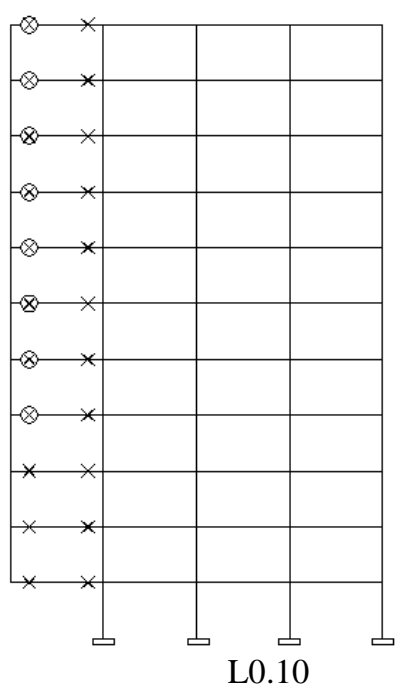

Immediate occupancy

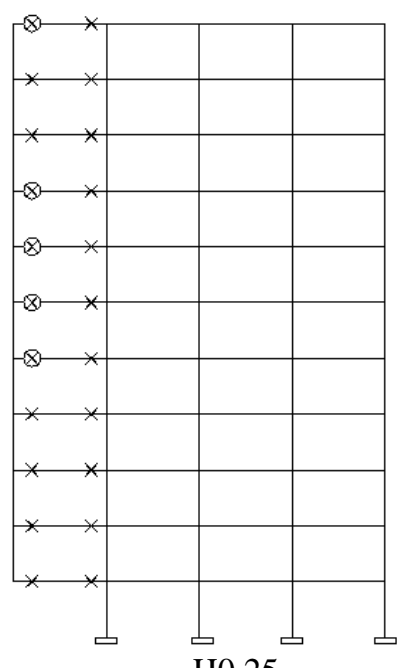

H0.25

Life safety

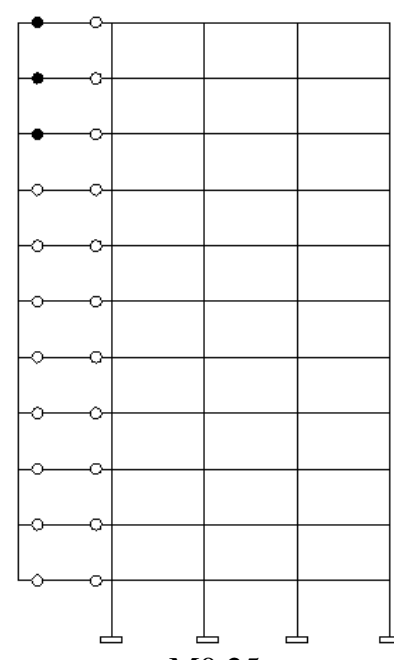

M0.25

$\otimes$ Collapse Prevention

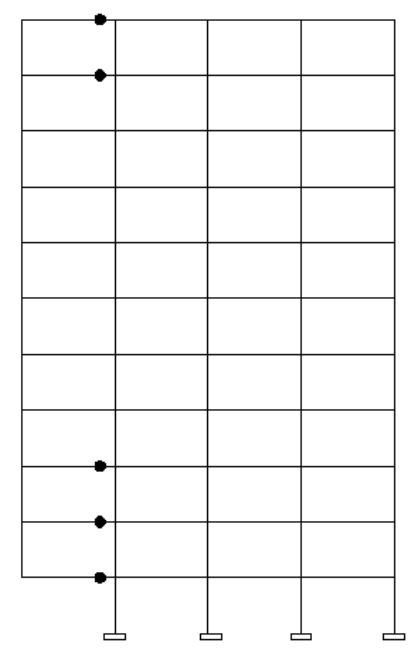

L0.25

$\times$ Collapse

Figure 5: Plastic Hinge Rotations at 2(G+0.25Q) for Case 3

Volume 6 Issue 1, January 2017

\author{
www.ijsr.net
}




\section{International Journal of Science and Research (IJSR)}

ISSN (Online): 2319-7064

Index Copernicus Value (2015): 78.96 | Impact Factor (2015): 6.391

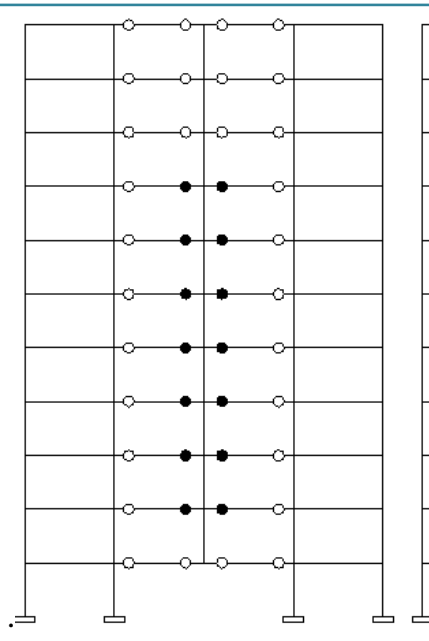

L0.10

Immediate occupancy

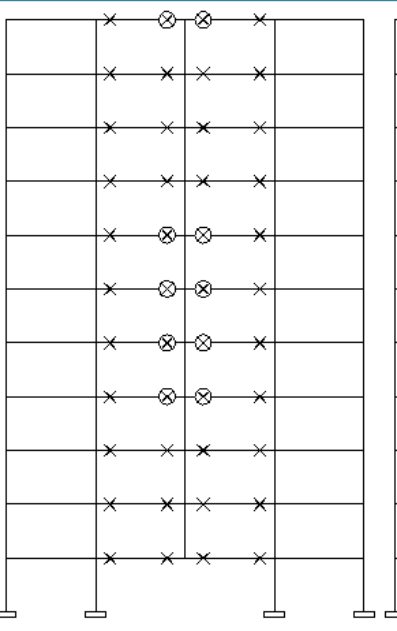

H0.25

Life safety

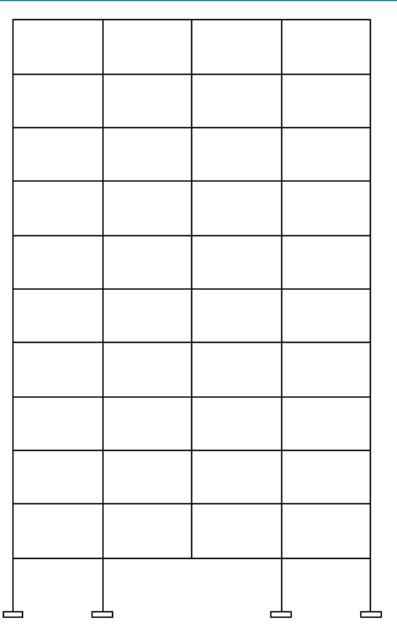

M0.25

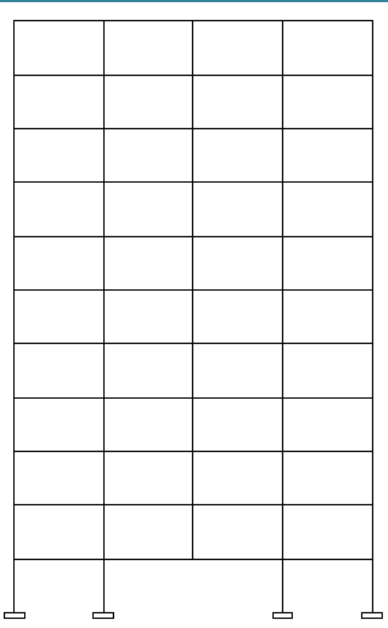

L0.25

$\times$ Collapse

Figure 6: Plastic Hinge Rotations at $2(\mathrm{G}+0.25 \mathrm{Q})$ for Case 4

\subsection{Vertical displacement Capacities}

The vertical displacement and the corresponding vertical loads for all the buildings are plotted in Figure 7 for the various column loss scenarios. The loading areas supported by the various removed columns vary; hence, the total vertical loads also vary for the columns. Therefore, the ratios of the vertical loads at each step to the specified total vertical load of $(\mathrm{G}+0.25 \mathrm{Q})$, known as Load Factors are used in the graph as a dimensionless loading parameter.

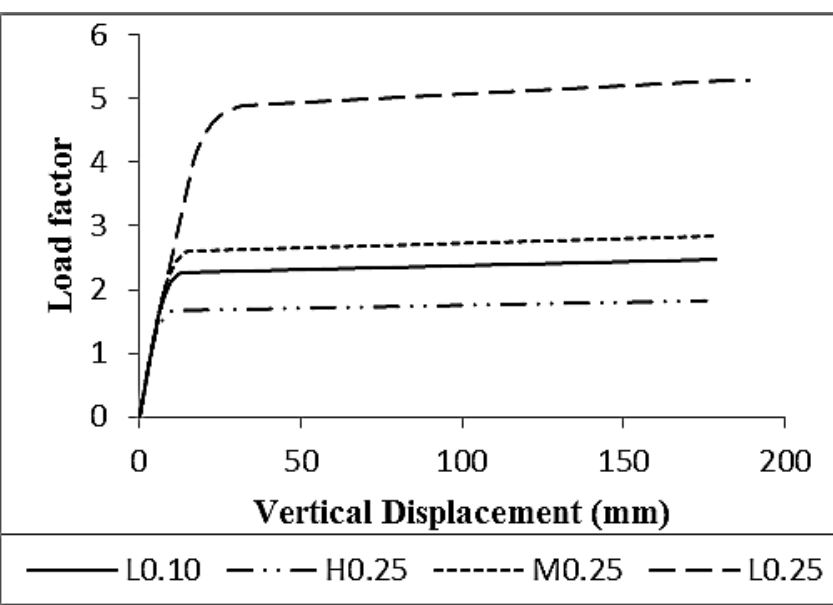

(a)

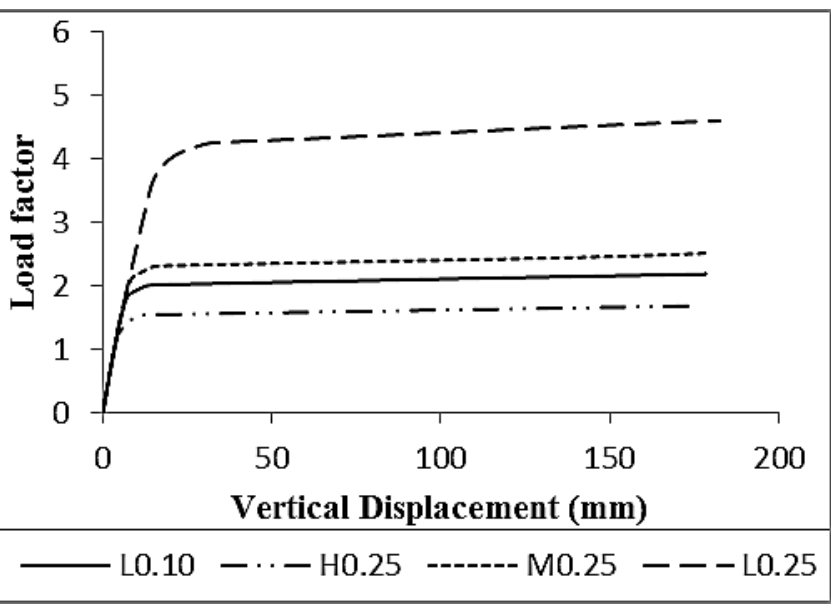

(b)

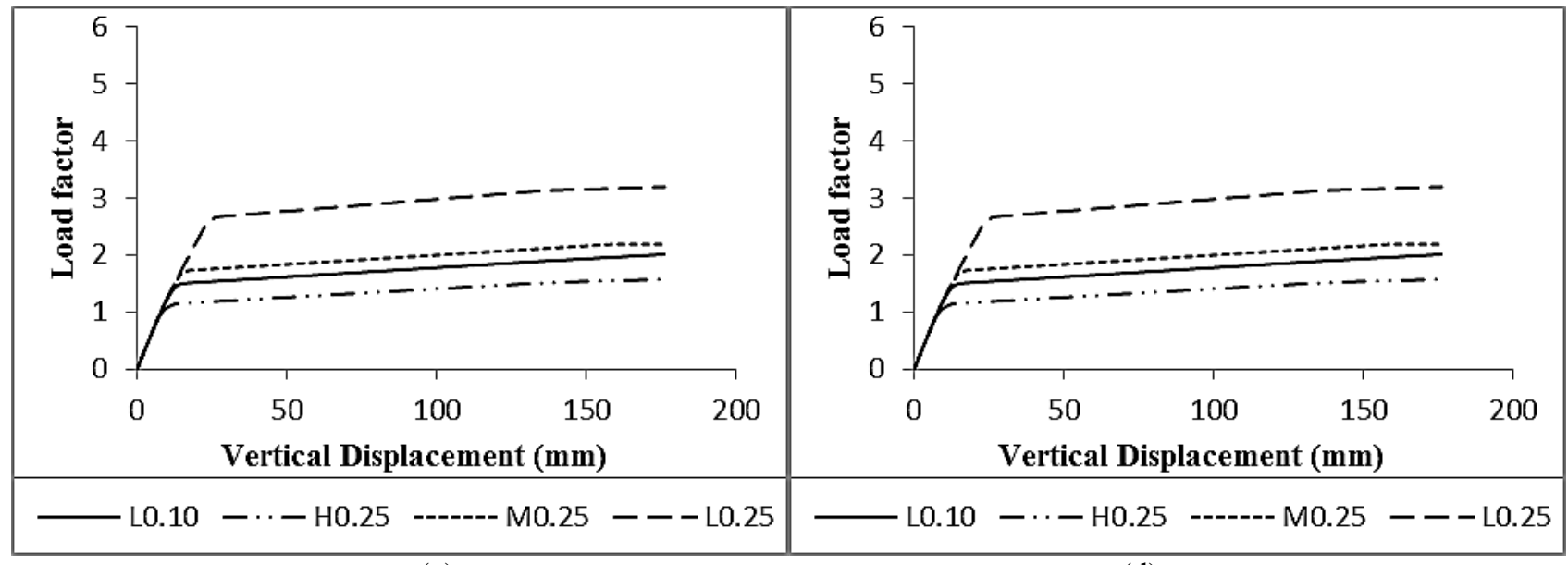

(c)

(d)

Figure 7: Load-displacement relations for (a) Case 1, (b) Case 2, (c) Case 3 and (d) Case 4

Volume 6 Issue 1, January 2017 www.ijsr.net 


\section{International Journal of Science and Research (IJSR) \\ ISSN (Online): 2319-7064}

Index Copernicus Value (2015): 78.96 | Impact Factor (2015): 6.391

\subsection{Effect of Design Ground Acceleration and Ductility Class}

From Figure 7, it is apparent that the resistance to progressive collapse of the structures increase with ground accelerations and lower ductility classes. It is observed that model L0.25, designed with $0.25 \mathrm{~g}$, had the highest collapse load factor of 5.3, 4.6, 3.2 and 4.3 in Cases 1, 2, 3 and 4 respectively. This makes them the most resilient to collapse. This is because it had the highest amount of reinforcement from the seismic design. As the design ductility classes increase at the same ground acceleration level in models M0.25 and H0.25, the collapse load factors were found to decrease.

Models L0.10 and L0.25 were designed ground accelerations of $0.10 \mathrm{~g}$ and $0.25 \mathrm{~g}$ respectively but the same ductility class. It is observed that, model L0.25 collapse at high load factors than model L0.10. The load factors for all models in the various cases are shown in Table 2 .

Table 2: Maximum Load Factors

\begin{tabular}{|c|c|c|c|c|}
\hline \multirow{2}{*}{$\begin{array}{c}\text { Column } \\
\text { Removal Case }\end{array}$} & \multicolumn{4}{|c|}{ Model } \\
\cline { 2 - 5 } Case 1 & 2.5 & H0.25 & M0.25 & L0.25 \\
\hline Case 2 & 2.2 & 1.8 & 2.8 & 5.3 \\
\hline Case 3 & 2.0 & 1.6 & 2.5 & 4.6 \\
\hline Case 4 & 2.1 & 1.6 & 2.2 & 3.2 \\
\hline
\end{tabular}

In general, it can be seen that, designing at high ground accelerations and low ductility classes increase the buildings resistance to progressive collapse. This observation is explained by the fact that, designing buildings to high seismic forces increases both negative and positive bending moment as well as shear force at both ends of the beams. This results in an increase in shear reinforcement and top and bottom longitudinal reinforcements at both ends of the beams. Higher design ground accelerations and lower ductility classes resulted in higher design seismic forces and hence higher section capacities of the structure.

Table 3: Vertical Ductilities

\begin{tabular}{|c|c|c|c|c|}
\hline \multirow{2}{*}{ Column Removal Case } & \multicolumn{4}{|c|}{ Model } \\
\cline { 2 - 5 } & L0.10 & H0.25 & M0.25 & L0.25 \\
\hline Case 1 & 17.6 & 24.2 & 15.3 & 8.6 \\
\hline Case 2 & 21.8 & 27.3 & 19.0 & 10.0 \\
\hline Case 3 & 8.6 & 5.3 & 10.3 & 6.1 \\
\hline Case 4 & 27.2 & 37.1 & 23.5 & 12.6 \\
\hline
\end{tabular}

Models with low ground accelerations and low ductility class, or high ground acceleration and high ductility classes were found to be having higher vertical ductilities as seen in Table 3. The vertical ductilities were calculated based on the reduced stiffness equivalent elasto-plastic yield method. The benefit of ductility, which includes suppressing brittle failure and provision of capacity to withstand nonlinear load, cycles without strength degradation can be useful since progressive collapse dynamic in nature [14]. It is worthy of note that this benefit may only be realized if the detailing rules defined in Eurocode 8 [14] are adhered to during construction.

\subsection{Effect of Removed Column Location}

The maximum load factors for the various column loss cases were plotted in Figure 8. By comparing maximum load factors, it was observed that the resistance of the structure to collapse is lowest when a corner column is lost (Case 3) since it has the lowest load factors and ductilities. The conclusion of the corner column loss case being the most critical is consistent with the findings of [17], [18] and [19] who all showed that reinforced concrete buildings were most vulnerable to progressive collapse when a corner column is lost.

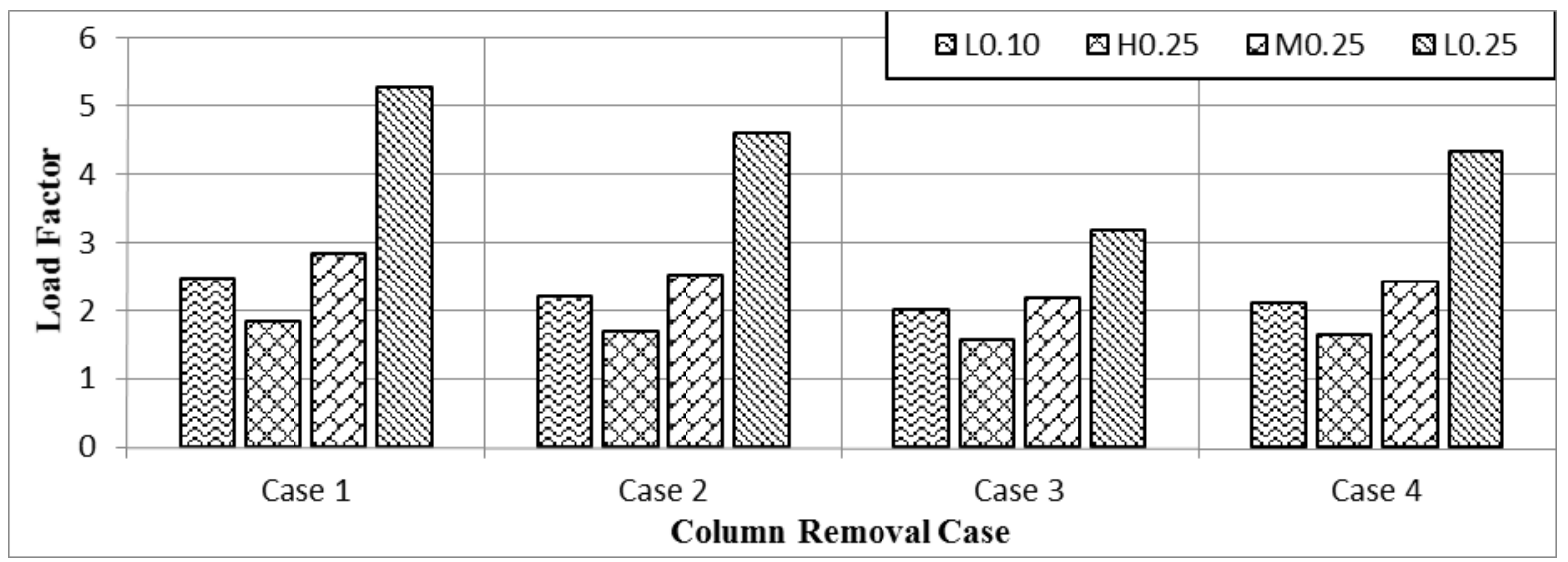

Figure 8: Maximum load factors for models for different column loss cases

The buildings had similar resistance when columns were lost from the short and longs sides. Maximum load factors varied from 1.8 in model H0.25 to 5.3 in model L0.25 for Case 1, 1.7 in model H0.25 to 4.6 in model L0.25 for Case 2 and 1.6 in model H0.25 to 4.3 in model L0.25 for Case 4. Model H0.25 is the only model found vulnerable to progressive collapse in all these cases because the GSA methodology prescribes a maximum load factor of 2.0 to assure resilience to progressive collapse.
Case 1 had slightly higher load factors than the other column removal cases, implying that the structures were found to be most resilient when a column is lost from a location near the middle of the short side of the building. [5] and[20] draw similar conclusions.

The removal an internal column (Case 4) generated lower load factors than Cases 2 and 3 but higher than Case 1. Model H0.25 is the only building that collapsed in this case with a load factor of 1.6. The load factors for the other models vary

\section{Volume 6 Issue 1, January 2017 www.ijsr.net}




\section{International Journal of Science and Research (IJSR) \\ ISSN (Online): 2319-7064}

Index Copernicus Value (2015): 78.96 | Impact Factor (2015): 6.391

from 2.1 in models L0.10, 2.4 in model M0.25 and 4.3 in L0.25. This however is counterintuitive to the principles underpinning the EC 8 design of earthquake structures in which structural members designed to different ductility classes are deemed to have collapse $d$ at different member rotations. The advantage of designing at a higher ductility class may however be useful if the structure is well detailed.

\section{Conclusion}

The vulnerability of reinforced concrete framed structures designed to Eurocode 8, with varying ground accelerations and ductility classes, to progressive collapse is investigated in this study. The effects of column removal location on the vulnerability of all the models were also compared. Four typical 11-storey RC framed structures were designed with ground accelerations of $0.10 \mathrm{~g}$ and $0.25 \mathrm{~g}$ at low, moderate and high ductility classes. Analysis of the progressive collapse vulnerability of these structures was carried out considering four column loss scenarios as specified by [8]. The analysis was carried out using the acceptance criteria specified by [8]. Based on the results presented and discussed, the following conclusions were drawn.

1. It was concluded that seismic design has a beneficial influence on the progressive collapse resistance of a reinforced concrete structure. Thus, the higher the ground acceleration, the more resistant the structure is to progressive collapse.It was also observed in this limited study that designing at a lower ductility class also positively increases a structures resistance to progressive collapse. This observation is counter-intuitive to the principles underpinning the EC 8 design code as higher design ductility class is expected to enhance the energy absorption capacity or ductility of buildings with same design seismic action but varying ductility classes. It is concluded that the use of GSA to assess buildings designed to EC 8 must be modified to include the effects of both design action and design ductility class of a structure. The advantage of designing at a higher ductility class may however be useful if the structure is welldetailed.

2. Structures are most vulnerable to progressive collapse when a corner column is lost. Hence, attention must be given to the design and detailing of beams connecting to these columns. Structures are most resilient to progressive collapse due to a column loss from the short side of the building.

\section{References}

[1] Taylor, D. A, (1975): "Progressive collapse", Canadian Journal of Civil Engineering, Volume 2, No 4

[2] WardhanaK,Hadipriono F. C,(2003): "Study of Recent Building Failures in the United States", Journal of Performance of Constructed Facilities, Volume 17, No.3

[3] Sasani M, Kropelnicki J, (2008): "Progressive Collapse Analysis of an RC Structure", The Structural Design of Tall and Special Buildings, vol.17, pp757-771.

[4] Kappos A, Penelis G. G, (2010): "Earthquake resistant concrete structures", CRC Press, pp607

[5] Ioani A. M, Cucu H. L, Mircea C, (2007): "Seismic design vs. Progressive Collapse: A Reinforced Concrete
Framed Structure Case Study", Proceedings of ISEC-4, Melbourne, Australia

[6] Marchiş A. G and Ioani A, M (2014): "The Risk for Progressive Collapse of RC Frame Structures Located in Seismic Areas in Romania" Construcţii - No.1/ 2014

[7] Singh R. S, Jamal Y. and Khan M. A. (2015): "Progressive Collapse Analysis of Reinforced Concrete Symmetrical and Unsymmetrical Framed Structures by ETABS", International Journal of Innovative Research in Advanced Engineering, ISSN: 2349-2763

[8] GSA (2003): "GSA Progressive Collapse Analysis and Design Guidelines for New Federal Office Buildings and Major Modernizations Projects", General Services Administration, USA

[9] DOD (2005): "Design of building to resist progressive collapse". Unified Facilities Criteria (UFC) 4-023-03, Department of Defence, USA

[10]FEMA-277, (1996): "The Oklahoma City Bombing: Improving Building Performance through Multi-Hazard Mitigation", Federal Emergency Management Agency

[11] Kaewkulchai G. and Williamson, E. B. (2003): "Dynamic behaviour of planar frames during progressive collapse" Proc., 16th ASCE Engineering Mechanics Conf., Seattle

[12] Powell G. (2005): "Progressive collapse: Case study using nonlinear analysis." Proc., 2005 Structures Congress and the 2005 Forensic Engineering Symp., New York.

[13] Marjanishvili S. M, (2004): "Progressive Analysis Procedure for Progressive Collapse", J. Perform. Constr. Facil., ASCE, 18(2), 79-85.

[14]EN 1998 (2005): Eurocode 8: "Design of structures for earthquake resistance", European Committee for Standardization

[15] Taewan K. Jinkoo K, Junhee P. (2009): “Investigation of Progressive Collapse-Resisting capability of Steel Moment Frames Using Push-Down Analysis", Journal of Performance of Constructed Facilities, Vol. 23, No. 5

[16]FEMA 356 (2000): "Prestandard and Commentary for the Seismic Rehabilitation of Buildings", Federal Emergency Management Agency, Washington, USA

[17] Baldridge S. M, Humay F. K, (2003): "Preventing Progressive Collapse in Concrete Buildings", Concrete International. Vol. 25, 73-79

[18] Ioani A. M, Cucu H. L, (2010): "Resistance to progressive collapse of RC structures: principles, methods and designed models", Computational Civil Engineering 2010, Iasi, Romania

[19] M. Adom-Asamoah M. and Ankamah N. O. (2016): "Effect of Design Ductility on the Progressive Collapse Potential of RC Frame Structures Designed to Eurocode 8", American Journal of Civil Engineering. Vol. 4, No. 2, 2016, pp. 24-33.

[20] Bilow D. N, Kamara M, (2004): “U.S. General Services Administration Progressive Collapse Design Guidelines Applied to Concrete Moment-Resisting Frame Buildings", ASCE Structures Congress, Nashville, Tennessee. 